\title{
Übersicht über die bei den anatomischen Namen verwendeten Zeichen und Abkürzungen
}

\begin{tabular}{c|c|c}
$\begin{array}{c}\text { \%cichen } \\
\text { crier Ab- } \\
\text { kürzung }\end{array}$ & verwendet bci & Bedeutung \\
\hline$*$ & Arterien, Nerven & Ursprung, Wurzelgebiet \\
$\rightarrow$ & Arterien, Nerven, Venen & Verlauf \\
$\leftrightarrow$ & Arterien, Nerven,Venen & Äste, Verzweigungen \\
$\rightarrow$ & Bändern, Muskeln & steht zwischen Ursprung und Ansatz \\
-1 & Venen & steht zwischen der Vene u. ihrem Quellgebiet \\
F. & Venen & Einmündung \\
I. & Muskeln & Funktion \\
S. & Vuskeln & Innervation \\
V. & Arterien, Nerven & Sammelgebiet \\
& & Versorgungsgebiet
\end{tabular}

